\title{
Deterministic and Stochastic Effects of Radiation
}

\author{
Sofiya Choudhary* \\ Radiotherapy Technologist, Jayothi Vidyapeeth Womens University, India
}

Submission: September 24, 2018; Published: October 05, 2018

"Correspondence Address: Radiotherapy Technologist, Jayothi Vidyapeeth Womens University, Jaipur, India, Email: r771980@gmail.com

\section{Radiation}

Energy that emitted from a source is referred as Radiation. Radiation is energy that travels through spaces. It can be defined as energy released in form of particles. It is in the form of waves or moving subatomic particles and rays. We can differentiate Radiation in two types.
a) Ionizing Radiation
b) Non-Ionizing Radiation

\section{Ionizing Radiation}

The Radiation which has very high energy is called Ionizing Radiation.it is dangerous and leaves bad impact on human body. Alpha, Beta, X-Ray are some examples of Ionization radiation.it has high energy and displace electron from there orbit. Creating charge atom and create D.N.A damage, outright cell death. Ionization Radiation is Radiation with enough energy so that during an interaction with an atom it can remove tightly bound electron from orbit. Causing the atom to become charged or ionized.

\section{Non-Ionizing radiation}

The type of Radiation is low energy Radiation no ion charge are produce in this Radiation. UV rays, Microwaves, Radiofrequency waves are some examples of Non-Ionizing Radiation. These rays are not directly harmful impact our lives. Depend heavily on these for survival. Non-Ionizing Radiation originates from various sources naturally originated or man -made this Radiation refer to any type of electromagnetic Radiation that does not carry enough energy per quantum to ionize atom or molecule that is to completely remove an electron from an atom or molecule. These are low energy Radiation not enough energy to pull electron from orbit but can excite the electron.

\section{Biological Effect Caused by Radiation}

The effect which occur in human body by the exposure from Ionizing Radiation. When the Radiation is fall on normal cell it causes the change in D.N.A of cell and effect the cell. The Radiation damage the cell and tissue of human body and all these effect on body by radiation are called Biological effect of Radiation. The potential biological effect and damages caused by Radiation depend on condition of Radiation exposure.

a. Quality of Radiation

\section{b. Quantity of Radiation \\ c. Received dose of Radiation \\ d. Exposure condition}

Radiation can cause immediate effect but also long-term effect which may occur in years or several generations later. Biological effect of Radiation results from both direct and indirect action of Radiation. Direct action is based on direct interaction between Radiation particles and complex body molecule.

Indirect is more complex and depend heavily on energy lose effect of Radiation in the body, tissue and the subsequent chemistry. Biological Effects are of two types

\section{a) 1.Deterministic Effect \\ b) Stochastic Effect}

\section{Deterministic effect}

Deterministic effects are also called non-stochastic effect. These effects depend on time of exposure, doses, type of Radiation.it has a threshold of doses below which the effect does not occur the threshold may be vary from person to person. Deterministic effects are those responses which increase in severity with increased dose if the dose increases the severity of an effect increases. All early effect and most tissue late effect is deterministic. Mechanism involve effect on many cells in these the severity of response is proportional to dose these are cell killing occur in all people when the dose is larger enough.

Deterministic effect includes

a) Acute Radiation Sickness

b) Chronic Radiation Sickness

\section{Acute radiation sickness}

Acute radiation effect is not dangerous effect these effects are mainly cause when the radiation dose must be large, and dose have been delivered in short time. These effect causes just after exposure or within 24 hours to exposure. These are easy to cure and control. Acute effect caused by a short exposure to a high level of toxin these effects cause by single exposure and result immediate health problem these effects generally manifests quickly often involves a high exposure over a short period. Mainly 
nausea, vomiting, headache, fever, skin and tissue burns are including in acute radiation sickness.

\section{Chronic radiation sickness}

Chronic radiation sickness occurs after a month or year of taking exposure in high amount. These effects are dangerous effect and difficult to cure and these may lead to death. Sometimes small dose of radiation continuously or over many years cause chronic effect. these effects are not immediate observable effect and may result in long term effect cataract, cancer, genetic mutation is some example of chronic effect. Chronic effect also includes temporary and constant sterility and inability to conceive baby.

\section{Stochastic effect}

Stochastic effect is those effect which occur when a person receives a high dose of radiation. These effects have an increase probability of occurrence with increase dose. There is no threshold dose below which is creatively certain that a stochastic effect cannot occur. Severity does not depend on magnitude of absorbed doses these effects occur by chance usually without threshold level of dose have no level of radiation dose effect arises from injury to one or a few cells.

Malignant disease and heritable effect for which the probability of effect occur. Occurrence of stochastic effect is probabilistic in nature and is proportional to dose received. Stochastic effect is of two types

This work is licensed under Creative Commons Attribution 4.0 License

DOI: 10.19080/CTOIJ.2018.12.555834 a) somatic stochastic effect

b) Genetic effect

\section{Somatic stochastic effect}

These effects of radiation limited to expose individual and they are distinguished from genetic effect. These effects are harming that expose individuals suffer during their lifetime.

\section{Genetic or heriditary effect}

The ionizing radiation damage the genetic material in reproductive cell and by the result of which these effects are transmits from generation to generation. Radiation induced material to an individual gene and D.N.A that can contribute to the birth of defective descendants.

\section{Conclusion}

Radiation is all around us in many different forms and it may be Ionizing or Non-Ionizing Radiation.it is very necessary to dealing with Radiation and its effect all the Radiation workers and their patient have to avoid the maximum doses of Radiation. Ionizing Radiation exposure to cell can affect the cell or change in cell D.N.A and change the nature of cell and sometimes it can kill the cell.it may cause immediate effect or not become apparent for long time. Radiation cause Biological effect and cause many diseases which may leads to death. Hence, there is an urgent need to take precautionary steps to avoid Biological Effect of Radiation.

\section{Your next submission with Juniper Publishers will reach you the below assets}

- Quality Editorial service

- Swift Peer Review

- Reprints availability

- E-prints Service

- Manuscript Podcast for convenient understanding

- Global attainment for your research

- Manuscript accessibility in different formats ( Pdf, E-pub, Full Text, Audio)

- Unceasing customer service

Track the below URL for one-step submission https://juniperpublishers.com/online-submission.php 